\title{
Absence of skeleton deposition in juveniles of the scleractinian coral Acropora millepora
}

Jeroen A.J.M. van de Water ${ }^{1,2,3,4}$, Madeleine J.H. van Oppen ${ }^{1,2,4}$, Bette L. Willis ${ }^{1,2,3}$

${ }^{1}$ ARC Centre of Excellence for Coral Reef Studies, ${ }^{2}$ AIMS@ JCU, ${ }^{3}$ School of Marine \& Tropical Biology, James Cook University, Townsville QLD 4811, Australia, ${ }^{3}$ Australian Institute of Marine Science, Townsville QLD 4810, Australia

Key Words: coral, calcification, skeleton, juvenile, spawning, settlement

Correspondence \& reprint requests to:

Jeroen van de Water

Phone: (+61) 0747815735

Facsimile: (+61) 747251570

e-mail: jeroen.vandewater@my.jcu.edu.au

This article is published in Coral Reefs (2012) - DOI: 10.1007/s00338-012-0935-7

The final publication is available at www.springerlink.com/content/m369080j624j1850 
Deposition of aragonite skeletons by scleractinian corals typically starts immediately after larval settlement and metamorphosis. However, following the November 2011 coral mass spawning event, we observed that many of our experimental Acropora millepora recruits still lacked a skeleton at 30 days following spawning.

Colonies of A. millepora collected from reefs surrounding Orpheus Island in the central Great Barrier Reef, Australia, spawned on 14 November 2011. Gametes were collected and fertilised, and developing embryos were transferred to larval rearing tanks (moderate aeration; 0.5 micron filtered sea water at $27^{\circ} \mathrm{C} ; 12$ hour light/dark cycles at $80 \mu \mathrm{E}$ light intensity). Settlement competency was observed after 6 days and larvae were settled onto terracotta tiles. Two days later, juveniles were exposed to clade D Symbiodinium for 12 hours and symbiosis was established in all recruits.

Non skeleton-depositing (Fig. 1a) and skeleton-depositing (Fig. 1b) coral juveniles were reared from the same mixture of gametes from $\sim 8$ parent colonies, and coexisted on settlement tiles as individual polyps or in aggregates. Although large aggregates appeared to consist of one phenotype only, i.e., either skeleton- or non skeleton-depositing (Fig. 1a, b), we observed both phenotypes growing side-by-side as primary polyps (Fig. 1c).

To our knowledge, this is the first description of non skeleton-depositing juveniles in scleractinian corals. The reasons for the lack of skeleton formation in these recruits are unknown. It is unlikely that non skeleton-depositing polyps represent cases of "polyp bailout" (Sammarco 1982), because empty corallites were not observed and skeletal structures were still absent at 24 days post-settlement, suggesting this may be a permanent state. It has been shown that adult corals can survive as skeleton-free polyps in an acidified environment (Fine and Tchernov 
2007). Since the environmental conditions under which skeleton-depositing and non skeleton-depositing coral juveniles were growing were identical, the cause of this phenomenon is likely to be of a (epi)genetic origin. Parentage and transcriptome analyses could provide valuable information on the genetic background of these individuals and identify key genes for skeleton formation.

\section{References}

Sammarco PW (1982) Polyp bail-out: an escape response to environmental stress and a new means of reproduction in corals. Mar Ecol Prog Ser 10:57-65

Fine M, Tchernov D (2007) Scleractinian coral species survive and recover from decalcification. Science 315:1811 

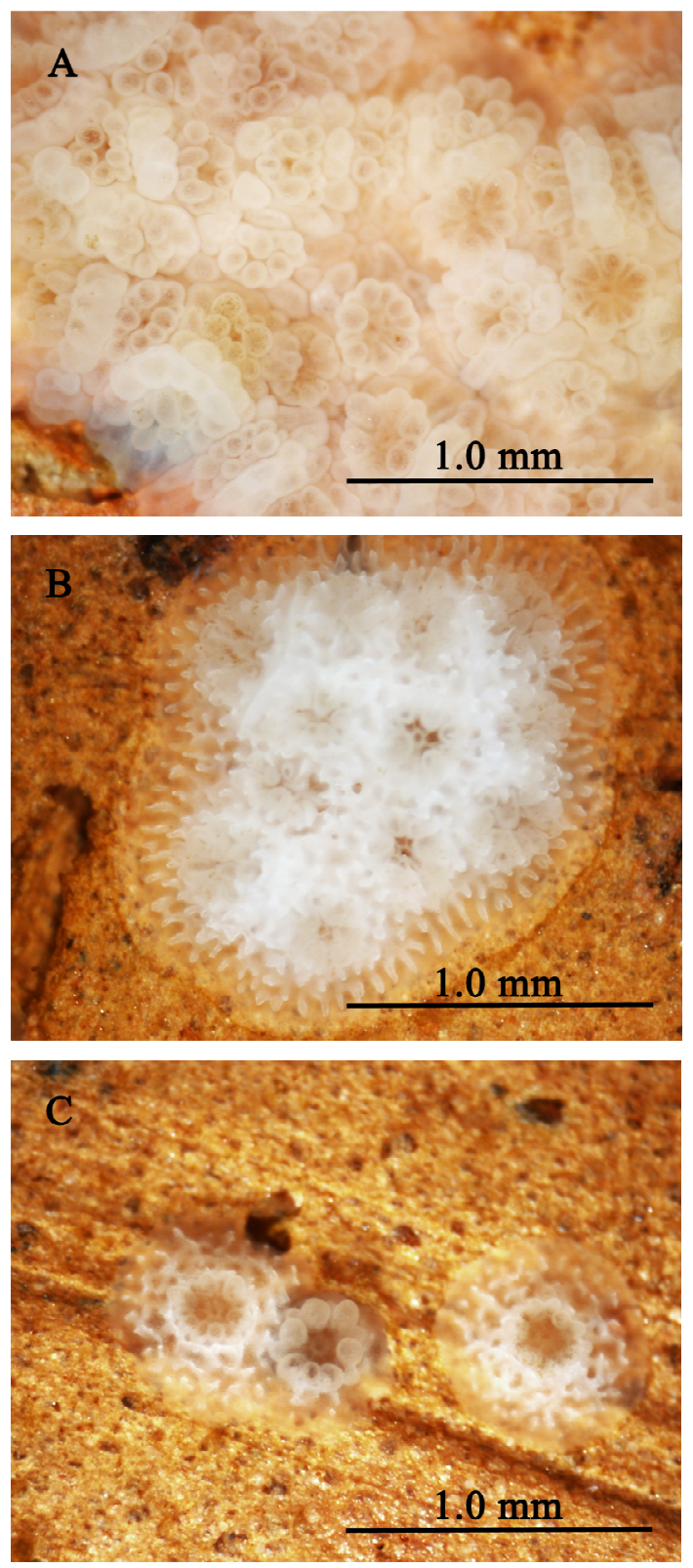

Figure 1: Non skeleton-depositing coral juveniles 12 days post-settlement. a Aggregation of non skeleton-depositing juveniles, b Aggregation of skeletondepositing juveniles, c Non skeleton-depositing and skeleton-depositing primary polyps. 